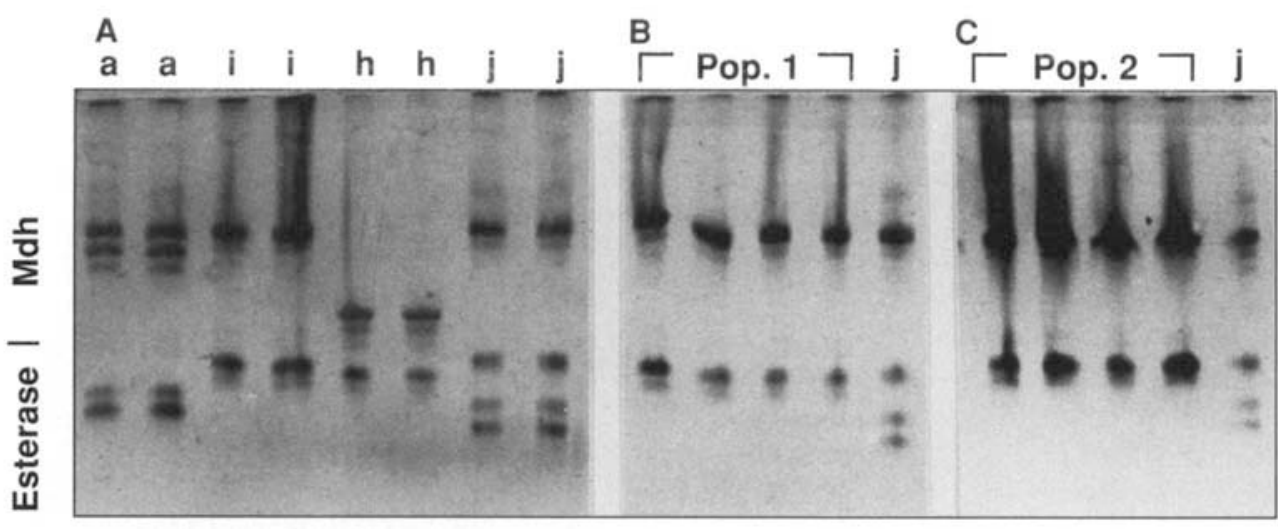

\section{"Resistance-breaking" nematodes identified in California tomatoes}

\author{
Isgouhi Kaloshian a Valerie M. Williamson $\square$ Gene Miyao \\ Dennis A. Lawn $\square$ Becky B. Westerdahl
}

\begin{abstract}
Resistance to root-knot nematodes in tomato is conferred by the gene Mi. We have identified two field populations of Meloidogyne incognita that parasitize tomato plants containing the Mi gene. This necessitates the use of planned crop rotation practices and the incorporation of other resistance genes into cultivated tomato.
\end{abstract}

Root-knot nematodes are important agricultural pests that parasitize a large number of cultivated crops worldwide. They cause serious yield loss to tomato crops, especially in warm temperate areas where soil temperatures favorable for nematode development result in quick build up of nematode populations.

Resistance to these nematodes is available in many varieties of both processing and fresh-market tomatoes. The resistance is conferred by a single dominant gene $M i$. To maximize the utility of $M i$, it is important to assess the potential for the establishment of resistance-breaking nematodes that can infect $M i$ plants in tomato-growing areas. Previous studies have shown that resistance-breaking populations can develop after continuous exposure to resistant varieties. The increasing reliance on resistance due to restricted use of nematicide treatments enhances the potential for selection of resistance-breaking populations in tomato fields.

\section{Root-knot nematodes}

Root-knot nematodes (Meloidogyne spp) are microscopic roundworms; they are obligate parasites of plant roots that cause severe damage to tomato and many other crops. The infective stage of the nematode, the secondstage juvenile (J2), penetrates the roots behind the root tip and migrates between the cells until it reaches the vascular bundle. The nematode starts feeding on selected cells near the vastransformed by the nematode into large multinucleate cells called "giant cells," which serve as a feeding site to provide nutrition for nematode development. Cells in the cortical layer of the root near the feeding site divide and enlarge to form galls, the common symptom associated with root-knot nematode infections. Above-ground symptoms include poor growth and wilting due to limited water transport through the disrupted plant vascular elcular bundle. These plant cells become
Fig. 1. Polyacrylamide gel showing the malate dehydrogenase (Mdh) and esterase phenotypes of single root-knot nematode females. Isozyme patterns of A) known isolates of $\boldsymbol{M}$. arenaria (a), $M$. incognita (i), M. hapla (h), and M. javanica (j); B) resistance-breaking nematodes from Woodland population (pop. 1), and $M$. javanica (j); C) resistance-breaking nematodes from Kettleman City population (pop. 2), and M. javanica (j).

ement at the nematode feeding site and to alterations in nutrient partitioning.

All resistance to root-knot nematodes present in commercial varieties of tomato is conferred by the Mi gene. This gene confers resistance to three species of root-knot nematodes, $M$. arenaria, $M$. incognita and $M$. javanica, the most common root-knot species found in tomato-growing areas in the United States. The resistance was originally identified in Lycopersicon peruvianum, a wild relative of cultivated tomato, and was introduced into cultivated tomato using embryo rescue of a cross of the wild species and cultivated tomato, $L$. esculentum, about 50 years ago. Embryo rescue is a technique in which embryos are dissected from partially developed seeds within tomato fruits and cultured aseptically on an artificial medium to enhance their growth. A single hybrid plant was recovered. Progeny of this plant are the sole source of nematode resistance in currently available freshmarket and processing tomato cultivars. Another decade of breeding was required to develop the first releases of nematode-resistant tomato lines.

Although $M i$ confers resistance to the three economically important species of root-knot nematode listed earlier, it does not confer resistance to $M$. hapla, a species also present in some areas of California where tomatoes are grown. In addition, the resistance conferred by $M i$ is not effective in soils where temperatures rise above $28^{\circ} \mathrm{C}$. Also, some isolates of $M$. incognita and $M$. javanica have been reported to cause galls and to reproduce on plants containing $\mathrm{Mi}$.

\section{Resistance-breaking nematodes}

In the fall of 1995, two occurrences of root-knot nematodes growing on resistant tomato cultivars in California fields came to our attention. One field was located near Kettleman City in Kings County. The second field was 
located at Woodland in Yolo County. In both cases, galling of the roots was extensive and the infection was widespread in the fields. We initiated a series of experiments to identify the nature of this problem. Since the Mi gene does not confer resistance to M. hapla, our first step was to identify the species of the root-knot nematode to eliminate the possibility of $M$. hapla infection. Adult females were dissected from the field-infected tomato roots and isoenzyme electrophoresis was carried out with individual females. Gels stained for malate dehydrogenase and esterase gave diagnostic patterns of $M$. incognita for both isolates (fig. 1). In addition, the symptoms on the tomato roots were typical large galls caused by $M$. incognita or $M$. javanica. $M$. hapla usually produces smaller galls with a "hairy" appearance.

To confirm that the galled plants in the field carried the $M i$ gene, we performed a molecular test to identify the presence of the REX-1 marker, a DNA marker that correlates with $\mathrm{Mi}$. This marker can be assayed on a small piece of leaf tissue using polymerase chain reaction and specific primers. Leaf tissue was available only from the tomato plants from the Woodland area. The analysis of the REX-1 marker showed that the plants were hybrids containing the $M i$ gene.

To confirm that these two root-knot nematode populations could reproduce on plants with $M i$, root-knot nematode eggs isolated from the roots of field-infected tomato plants were used to infect tomato variety 'VFNT,' which is known to contain the $M i$ gene. 'UC82-B,' a tomato cultivar that does not have $M i$, was included as a susceptible control. Tomato seeds were germinated in 1-liter cups in river sand and plants were grown in a greenhouse. For each nematode population, three seedlings of 'VFNT' and 'UC82-B' were infected with 10,000 eggs each and maintained in the greenhouse at $23^{\circ}$ to $26^{\circ} \mathrm{C}$. After 8 weeks, we washed the plant roots and estimated nematode reproduction by counting egg masses on the roots. Both field populations of root-knot nematodes were able to reproduce to high levels on 'VFNT,' as well as on control 'UC82-B.' We counted more than 100 egg masses per root system on both tomato varieties infected with the Woodland or the Kettleman City rootknot nematode populations. Standard nematode populations produce 0 to 5 egg masses on 'VFNT' in similar assays.

Although nematodes from both locations were able to reproduce on resistant tomato plants, the histories of the two fields were quite different. The field in Woodland had been planted with six crops of tomato within a 10-year period; all varieties were processing-type hybrids containing the $M i$ gene. The pressure exerted on the nematode population by the frequent cultivation of resistant tomato could explain the development of the resistance-breaking population. On the other hand, the field from Kettleman City had been planted with only two tomato crops immediately prior to the infected crop in 1995, and had been left fallow for the 8 previous years. Records are not available regarding the varieties of tomato planted. In addition, there were some nematode problems with the first tomato crop, but little importance was placed on it. This population of rootknot nematode may have had an inherent capability to grow on Mi-containing plants. Although such populations of $M$. incognita are not thought to be common in California, they have been reported in other parts of the world.

\section{Dealing with the problem}

Root-knot nematodes are serious pests of tomato worldwide. Restrictions on the use of most nematicides coupled with the availability of $\mathrm{Mi}$ resistance in many preferred tomato varieties have led farmers to rely increasingly on resistant tomatoes for nematode management. Repeated plantings of resistant tomato may lead to the selection of resistance-breaking root-knot populations on some sites. Because all root-knot resistance in tomato is conferred by the same gene, the substitution of one cultivar for another will not be helpful. Increased awareness of proper rotation practices of resistant tomato with other crops will extend the durability of the $M i$ gene.

The recent emergence in California of root-knot nematode populations

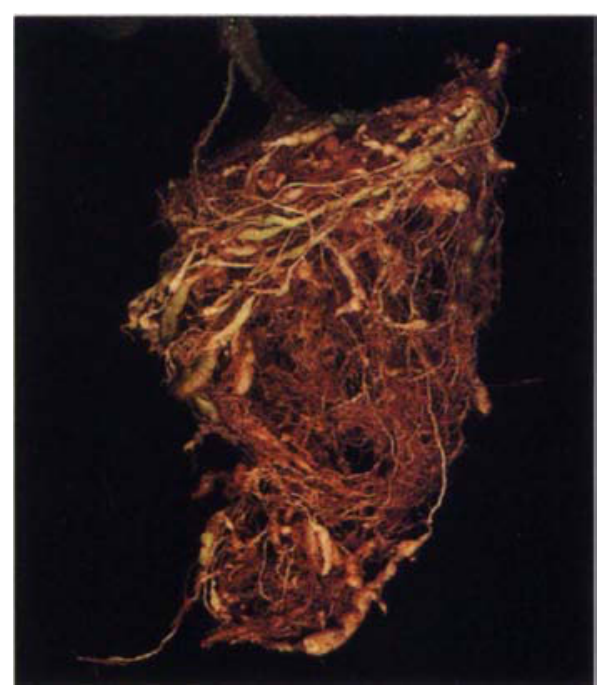

Root-knot nematodes collected from resistant tomato plants at Woodland were able to produce galls on the roots of the resistant 'VFNT' tomato.

that can overcome the resistance conferred by $M i$ is a cause for concern. However, it is difficult to assess the magnitude of the threat from resistance-breaking nematodes based on these isolated finds with different cropping histories. Some populations have been shown to lack genetic potential for resistance breaking in controlled selection experiments. Furthermore, there is evidence that $M i$-resistance-breaking populations are not able to break resistance in other crops. New sources of resistance to root-knot nematodes have been identified in wild tomato, but it will take many years of effort before they are in acceptable varieties. Development of novel resistance by using biotechnology to produce transgenic plants has promise for providing another source of resistance. Research to incorporate both natural and engineered resistance into cultivars as well as investigation of the biology of the nematode is needed in order to develop additional control strategies for rootknot nematode in the years to come.

I. Kaloshian, V.M. Williamson and B.B. Westerdahl are Postdoctoral Fellow, Associate Professor, and Extension Nematologist, respectively, Department of Nematology, UC Davis; G. Miyao is Farm Advisor Yolo/Solano Counties; and D.A. Lawn is Plant Pathologist, Seminis Vegetable Seed Inc., San Juan Bautista. 